\title{
Estimating fog-top height through near-surface micrometeorological measurements
}

ARTICLE in ATMOSPHERIC RESEARCH · NOVEMBER 2015

Impact Factor: 2.84 · DOI: 10.1016/j.atmosres.2015.11.016

READS

108

6 AUTHORS, INCLUDING:

Carlos Yagüe

Complutense University of Madrid

83 PUBLICATIONS 651 CITATIONS

SEE PROFILE

Jon Ander Arrillaga

Complutense University of Madrid

3 PUBLICATIONS 0 CITATIONS

SEE PROFILE
Gert-Jan Steeneveld

Wageningen University

169 PUBLICATIONS 1,647 CITATIONS

SEE PROFILE

Gregorio Maqueda

Complutense University of Madrid

37 PUBLICATIONS 183 CITATIONS

SEE PROFILE 


\section{Accepted Manuscript}

Estimating fog-top height through near-surface micrometeorological measurements

Carlos Román-Cascón, Carlos Yagüe, Gert-Jan Steeneveld, Mariano Sastre, Jon Ander Arrillaga, Gregorio Maqueda

PII:

S0169-8095(15)00387-7

DOI:

doi: 10.1016/j.atmosres.2015.11.016

Reference:

ATMOS 3563

To appear in: $\quad$ Atmospheric Research

Received date: 31 July 2015

Revised date: $\quad 24$ November 2015

Accepted date: 27 November 2015

Please cite this article as: Román-Cascón, Carlos, Yagüe, Carlos, Steeneveld, Gert-Jan, Sastre, Mariano, Arrillaga, Jon Ander, Maqueda, Gregorio, Estimating fog-top height through near-surface micrometeorological measurements, Atmospheric Research (2015), doi: $10.1016 /$ j.atmosres.2015.11.016

This is a PDF file of an unedited manuscript that has been accepted for publication. As a service to our customers we are providing this early version of the manuscript. The manuscript will undergo copyediting, typesetting, and review of the resulting proof before it is published in its final form. Please note that during the production process errors may be discovered which could affect the content, and all legal disclaimers that apply to the journal pertain. 


\title{
Estimating fog-top height through near-surface micrometeorological measurements
}

\author{
Carlos Román-Cascón ${ }^{\mathrm{a}}$, Carlos Yagüe ${ }^{\mathrm{a}}$, Gert-Jan Steeneveld ${ }^{\mathrm{b}}$, Mariano Sastre ${ }^{\mathrm{a}}$, Jon Ander Arrillaga ${ }^{\mathrm{a}}$, Gregorio \\ Maqueda ${ }^{\mathrm{c}}$ \\ ${ }^{a}$ Dept. de Geofísica y Meteorología. Universidad Complutense de Madrid. Madrid, Spain. \\ ${ }^{b}$ Meteorology and Air Quality Section. Wageningen University. Wageningen, The Netherlands. \\ ${ }^{c}$ Dept. de Física de la Tierra, Astronomía y Astrofísica II. Universidad Complutense de Madrid. Madrid, Spain.
}

\begin{abstract}
Fog-top height (fog thickness) is very useful information for aircraft manoeuvres, data assimilation/validation of Numerical Weather Prediction models or nowcasting of fog dissipation. This variable is usually difficult to determine, since the fog-layer top cannot be observed from the surface. In some cases, satellite data, ground remote-sensing instruments or atmospheric soundings are used to provide approximations of fog-top height. These instruments are expensive and their data not always available. In this work, two different methods for the estimation of fog-top height from field measurements are evaluated from the statistical analysis of several radiation-fog events at two research facilities. Firstly, surface friction velocity and buoyancy flux are here presented as potential indicators of fog thickness, since a linear correlation between fog thickness and surface turbulence is found at both sites. An operational application of this method can provide a continuous estimation of fog-top height with the deployment of a unique sonic anemometer at surface. Secondly, the fog-top height estimation based on the turbulent homogenisation within well-mixed fog (an adiabatic temperature profile) is evaluated. The latter method provides a high percentage of correctly-estimated fog-top heights for well-mixed radiation fog, considering the temperature difference between different levels of the fog. However, it is not valid for shallow fog ( less than $50 \mathrm{~m}$ depth), since in this case, the weaker turbulence within the fog is not able to erode the surface-based temperature inversion and to homogenise the fog layer.
\end{abstract}

Keywords: radiation fog, stability, turbulence, mixing, fog-top

\section{Introduction}

Fog is a troublesome phenomenon affecting the daily life of humans. Among these problems, numerous flight cancellations, delays and landing diversions to other airports are caused by foggy conditions at airports (Fabbian et al., 2007; Stolaki et al., 2012). This implies substantial costs to aerial companies and airports, comparable to the cost related to damage by tornadoes (Gultepe et al., 2007). However, fog is still poorly reproduced by Numerical Weather Prediction (NWP) models (Bergot et al., 2007; Román-Cascón et al., 2012; Price et al., 2015; Steeneveld et al., 2015). In the case that they are represented, numerical models have problems simulating the fog vertical extension (e.g., Guedalia and Bergot,

Email address: carlosromancascon@ucm.es (Carlos Román-Cascón)

Preprint submitted to Atmospheric Research
1994; Román-Cascón et al., 2012; Shi et al., 2012), specially for shallow fog and, in part, due to the limited vertical resolution of models.

Furthermore, it is important to have good estimations of observed fog-top height for validation of model simulations, since comparisons between observed and simulated fog thickness cannot be performed in many cases due to the lack of fog-top observational data. Moreover, there is no doubt about the importance of an accurate information of fog thickness for data assimilation of NWP models, due to the significant impact of this parameter on the radiation budget close to the surface (Rémy and Bergot, 2009). It is also crucial to improve the nowcasting of fog dissipation, since the clearing of deeper radiation fog requires more time than for shallower fog. Finally, the knowledge of the fog-top height can be a quite meaningful information for aircraft pilots when they are landing in foggy conditions, specially in poten-

November 24, 2015 
tial emergency cases without Instrument Landing System (ILS). Most airports have regulatory meteorological instrumentation composed by surface visibilimeters, a ceilometer (measuring cloud base and cloud cover) and standard meteorological instrumentation, but all these data are not enough to provide information about fogtop height.

Despite the numerous potential applications of this variable, its numerical value is not always clear. Many studies cannot provide information about observed fogtop height due to the lack of measurements in the vertical. In many cases, temperature and humidity data from atmospheric soundings are used to estimate fog thickness (e.g., Koračin et al., 2001; Liu et al., 2011; Boers et al., 2013; Bari et al., 2015). However, these soundings are not always available, or their temporal frequency is not sufficient to cover the whole fog cycle. In other cases, remote sensing instruments are used to estimate the fog top. Dabas et al. (2012) studied the ability of using reflectivity measurements from sodar to estimate fog-top height, while Boers et al. (2013) derived visibility from radar reflectivity for a case study of radiation fog. Ceilometers detect cloud-base height of low clouds (e.g., Dupont et al., 2012), but they are not useful to provide information about fog-top height. All these instruments are usually expensive and sometimes their vertical resolution is not appropriate compared to the fog thickness.

On the other hand, data or products from satellite have been widely used to detect fog or low clouds in numerous fog analyses (e.g., Reudenbach and Bendix, 1998; Van der Velde et al., 2010). Ellrod (1995) developed a technique to approximate fog thickness from brightness differences of two IR channels. Thereafter, Brenguier et al. (2000) related cloud thickness with liquid-water path from remote sensing using an adiabatic model, assuming liquid water content (LWC) increasing from cloud base to the cloud top. In these cases, difficulties appear when trying to differentiate between fog and low clouds (Cermak and Bendix, 2008; Yi et al., 2015). Thus, Bendix et al. (2005) proposed the determination of low stratus thickness and top height of clouds (fog) from MODIS daytime data in order to differentiate between low clouds and fog. Alternatively, Cermak and Bendix (2011) developed a method for the determination of low-stratus thickness from MSGSEVIRI data. However, most of these methods have to estimate liquid water path from satellite, and in some cases their accuracies exceed the high vertical resolution required for fog studies. Besides, thin cirrus can also obstruct the detection of fog and the availability of the data needed for these approaches can be limited in some cases, for example during night-time conditions.

In any case, fog is defined as a visibility threshold (surface horizontal visibility $<1000 \mathrm{~m}$, (DOC/NOAA, 1995)), but unfortunately, only a few works have the opportunity of using visibilimeters deployed at different heights to determine the fog top (e.g., Guedalia and Bergot, 1994).

In this work, on the one hand we have found a clear linear correlation between surface turbulence and fogtop height. Thus, regression equations are derived relating friction velocity and buoyancy flux at surface with fog thickness data. These relations are statistically calculated by using data from numerous radiation fog events at two sites: the Cabauw Experimental Site for Atmospheric Research (CESAR) in The Netherlands and the Research Centre for the Lower Atmosphere (CIBA) in Spain. A potential applicability of this method could provide a continuous estimation of fogtop height during radiation-fog events with the deployment of a unique sonic anemometer close to the surface.

On the other hand, statistics are performed in order to evaluate the estimation of fog thickness through temperature measurements in the vertical. The temperature homogenization within well-mixed fog is a well-known process which causes temperature convergence at the levels where the fog is present (Nakanishi, 2000; Porson et al., 2011; Ye et al., 2015). Furthermore, Price (2011) suggested that temperature convergence did not occur for shallow fog, although he was not able to demonstrate this issue, since his statistical observational study did not include fog thickness. Herein, we compare observed fog thickness (through visibility measurements at several heights) with estimations of fog-top height based on differences between temperature measured at several levels. We have found how the performance of the method strongly depends on the fog thickness and it is not valid for shallow fog. However its application is also limited for deeper fog ( $\sim 200 \mathrm{~m}$ depth). To conclude, a long-lasting event of radiation fog is analysed at CESAR in order to determine the applicability and skill of these methods during a complete fog cycle.

The study is organised as follows: section 2 presents information about the observational data and experimental sites. Section 3 shows the results for both methods and their evaluation for a case-study at CESAR. Finally, a short discussion and conclusions are presented in Section 4.

\section{Data and methodology}

This work uses data from two different experimental sites: the Cabauw Experimental Site for Atmospheric
4 
Research (CESAR, Beljaars and Bosveld (1997)) and the Research Centre for the Lower Atmosphere (CIBA, Cuxart et al. (2000)).

CESAR is located in The Netherlands $\left(51^{\circ} 58.22 \mathrm{~N}\right.$, $4^{\circ} 55.57 \mathrm{E},-0.7 \mathrm{~m}$ above sea level (asl)), over a flat and quite humid terrain surrounded by grass, water canals and pasture. It is $40 \mathrm{~km}$ south from the North Sea and very close to the moderately-high populated area of Utrecht-Amsterdam. A 213-m mast stands at CESAR (Figure 1) with many meteorological instruments from different institutes. However, only a few of them (indicated in Figure 1) were necessary for this study.

CIBA site is located in the Northern Spanish Plateau $\left(41^{\circ} 48.92 \mathrm{~N}, 4^{\circ} 55.92 \mathrm{~W}, 850 \mathrm{~m}\right.$ asl), over Los Montes Torozos, which is a homogeneous and extensive plateau $\left(800 \mathrm{~km}^{2}\right)$. CIBA site is located over a quite dry terrain surrounded by crop areas (pasture, cropland and shrubland), far from the sea, mountains or high populated areas. The height of the mast at CIBA is $100 \mathrm{~m}$, instrumented at different levels (see details in Figure 1).

Due to the permanent basis of the meteorological devices at the two experimental sites, the instruments differ between one place and another, as well as the heights where they were installed. At CIBA, a METEK-USA-1 sonic anemometer was available at $1.5 \mathrm{~m}$ above ground level (agl), measuring at a frequency of $20 \mathrm{~Hz}$ and using 5-minutes averages for the calculation of the buoyancy flux or friction velocity from wind components and temperature. At CESAR, a GILL R3 sonic anemometer is installed at $3 \mathrm{~m}$ agl, measuring at a frequency of $10 \mathrm{~Hz}$, while the surface fluxes and turbulent parameters are calculated from 10-minutes averages. Sonic anemometers measurements at both places are validated from analyses of time series and outliers are removed (gap-filled in the case of CESAR in some cases), besides the automatic malfunctioning checking of dataloggers. Tilt corrections are also applied to the data and finally, turbulent parameters at both places are averaged into 10-minutes data for the calculations performed in the present work.

Temperature measurements are obtained from Theodor Friedrichs 3032.02 (Pt 100) at CIBA and from E \& E thermocouples (Pt 1000 - Pt 500) at CESAR. Finally, BIRAL SWS-100 visibilimeters (at both places) were used to provide horizontal visibility data, based on the atmospheric extinction coefficient, which is proportional to the liquid water content of the air. These instruments were deployed at different heights $(2,10,20,40,70,140$ and $200 \mathrm{~m}$ agl at CESAR and 2, 30, 70 and $100 \mathrm{~m} \mathrm{agl}$ at CIBA). They were configured to measure with a maximum visibility range of $20 \mathrm{~km}$. Due to the necessity of visibility measurements at several heights to carry out this study, data from fog events within the period comprising from April 2011 to December 2013 and from 24 December 2014 to 14 January 2015 were used at CESAR and CIBA respectively (Table I). The starting dates of these periods coincide with the installation of the commented visibility devices at each site.

In this work, fog is defined when the surface visibility $(2 \mathrm{~m} \mathrm{agl})$ is lower than $1000 \mathrm{~m}$ (as defined in DOC/NOAA (1995)). An independent fog event is then defined when data-slots reporting fog are separated more than 2 hours. However, only fog events with more than 2 hours of persistence and with $60 \%$ of data slots reporting fog are considered, in order to avoid short-lived, patchy and non-well established fog events. Similar procedures have been used in previous works (Menut et al., 2014; Román-Cascón et al., 2015). Finally, only radiation-fog or cloud-base lowering (cbl) fog events are analysed, which have been classified according to the classification presented in Tardif and Rasmussen (2007). Therefore, advection or precipitation fog events have not been included in this study, since the physical mechanisms involved in their formation are different than those for radiation and cloud-base lowering fog events. Thus, a total of 84 radiation-fog events are used at CESAR and 18 at CIBA, corresponding to 2569 data (10-min time slots) with fog (428 hours) at CESAR and 1094 (182 hours) at CIBA (see Table I).

\section{Results}

\subsection{Fog thickness estimation from surface turbulent measurements}

In this section, we show how surface turbulent parameters calculated from sonic anemometer measurements can provide satisfactory estimations of the fogtop height.

\subsubsection{Estimation with friction velocity}

Firstly, surface friction velocity $\left(u_{*}\right)$ values are calculated from high frequency measurements of sonic anemometers (Eq.1) at both sites:

$$
u_{*}=\left[\left(-\overline{u^{\prime} w^{\prime}}\right)^{2}+\left(-\overline{v^{\prime} w^{\prime}}\right)^{2}\right]^{0.25},
$$

whence $u^{\prime}, v^{\prime}$ and $w^{\prime}$ are the fluctuations respect to average values of the two horizontal and the vertical components of the wind measured by sonic anemometers. Subsequently, $u_{*}$ values are averaged into 10 -min data and compared with their associated values of fog thickness for all considered fog events at each site. It has not been considered only in the mature stage of 
each event, but in the whole fog cycle, due to the observed high correlation between the value of this turbulent parameter and the growing or decaying of the fog layer. Note that we only include data when the visibility $<1000 \mathrm{~m}$ at $2 \mathrm{~m}$ agl, i.e., when fog is reported at the lowest level. Fog thickness was estimated from visibility measurements at different heights at each site (see Figure 1 for differences between sites) and it is assigned to the midpoint between the maximum height where the visibility is $<1000 \mathrm{~m}$ and the height of the next visibilimeter up in the tower (where visibility is $>1000 \mathrm{~m}$ ). In the case of visibility $<1000 \mathrm{~m}$ at the highest level with availability of visibility measurements ( $200 \mathrm{~m} \mathrm{agl}$ at CESAR and $100 \mathrm{~m}$ agl at CIBA), fog thickness is estimated to be equal to the corresponding level at each site, since there is no more information above these heights, although this can represent an underestimation.

Figure 2 shows the mean friction velocity calculated for each fog thickness value (discrete values). Vertical dotted blue lines indicate the uncertainty in the fog thickness, given by the height differences between adjacent visibilimeters. Horizontal dotted blue lines show the standard deviation of the set of friction velocity measurements for each fog-top height. Afterwards, linear adjustments for fog-top height $\left(Z_{f-t}\right)$ and $u_{*}$ were calculated for each site and are expressed with red dashed lines in both figures, corresponding to Eq. 2 at CESAR and Eq. 3 at CIBA:

$$
\begin{aligned}
& Z_{f-t}=1369 u_{*}-28, \\
& Z_{f-t}=1029 u_{*}-30,
\end{aligned}
$$

where $Z_{f-t}$ is obtained in meters if $u_{*}$ is provided in $\mathrm{m} \mathrm{s}^{-1}$. The coefficient of determination $\left(R^{2}\right)$ is substantially high for both sites (0.974 at CESAR and 0.982 at CIBA), which highlight the linear relation between these two parameters. The trend is statistically significant in both cases (T-student significance test with $95 \%$ of confidence). Nevertheless, the relatively extensive length of horizontal error bars should be noted, specially for deeper fog, which indicates the spreading over a wide range of values. However, the fluctuating nature of a turbulent parameter as $u_{*}$ and the use of 10-minutes data in this study make the use of $u_{*}$ mean values appropriate for the linear regression.

The intercepts -28 and -30 in Equations 2 and 3 or the point where the lines cross the $\mathrm{x}$-axis of Figures $2 \mathrm{a}$ and $2 \mathrm{~b}$ respectively are interpreted as the minimum turbulence needed to form radiation fog. These values are quite similar at both sites (around $0.025 \mathrm{~m} \mathrm{~s}^{-1}$ at CESAR and $0.03 \mathrm{~m} \mathrm{~s}^{-1}$ at CIBA). Hence, according to the linear regression, no fog will be formed (or it will be a fog shallower than $2 \mathrm{~m}$ ) below these thresholds and these are the minimum turbulence values required to start forming a (very shallow) fog at each site. Oppositely, $u_{*}$ maxima values for deep fog provide an indication of the turbulence required to dissipate the fog, since no fog is observed above these limits. Although $u_{*}$ outliers can appear during fog events, values larger than $0.2 \mathrm{~m} \mathrm{~s}^{-1}$ at CESAR and $0.15 \mathrm{~m} \mathrm{~s}^{-1}$ at CIBA are rarely observed and they can be related to the transformation of fog into low clouds (dissipation at surface).

Green dotted-dashed lines in Figure 2 ( $a$ and b) show the regression line for the other site for a clearer comparison. In the case of CESAR, most analysed fog events in this study have less thickness than $200 \mathrm{~m}$, and this height is normally exceeded by the fog only for short time intervals (only $9 \%$ of fog time with fog-top height equal or higher than $200 \mathrm{~m}$ ). Therefore, we consider that the mean $u_{*}$ value obtained for 200-m fog does not correspond to fog much deeper than $200 \mathrm{~m}$. However, at CIBA many fog events ( 9 events from 18 considered, $55 \%$ of fog total time) exceeds the $100-\mathrm{m}$ level and therefore the mean $u_{*}$ associated with $100-\mathrm{m}$ fog could not correspond to fog with thickness of 100-m, but some tens of meters more. Consequently, the slope of the line obtained at CIBA (green dotted-dashed line in Figure $2 \mathrm{a}$ or red dashed line in Figure $2 \mathrm{~b}$ ) would become more similar to the CESAR one (red dashed line in Figure $2 \mathrm{a}$ or green dotted-dashed line in Figure 2b). In any case, lower values of turbulence are found within radiation fog at CESAR compared to CIBA values, which can be due to differences between sonic instruments (GILLR3 at CESAR and METEK-USA1 at CIBA), or to the height where they were installed ( $3 \mathrm{~m}$ agl at CESAR and $1.5 \mathrm{~m}$ agl at CIBA). Besides this, the results could also be affected by a possible site-dependence related to differences between sites, such as local heterogeneities, surface humidity differences affecting the strength of turbulence (Sastre et al., 2015), etc. Therefore, future comparisons with other sites with different surface and local characteristics are specially encouraged.

Figures 3 and 4 show the frequency plots of friction velocity measured for each fog-top height at CESAR and CIBA respectively. Vertical blue lines indicate the mean of these values (used in Figure 2 for the linear regression), which are similar to median values. The number of considered data for each fog thickness is indicated with $n$, which is considerably larger for 6-m fog at CESAR $(n=1408)$ (note that $6-\mathrm{m}$ fog is defined as fog observed at the level of $2 \mathrm{~m}$ agl but not at $10 \mathrm{~m}$ agl). This indicates that most fog events at CESAR are very shallow ones, which are formed in spring and summer after convective rains. Since this number is quite 
high, the frequency distribution for 6-m fog at CESAR includes more outliers and therefore it has a relatively long tail towards larger values of friction velocity, compared to fog with other thickness. Many of these relatively higher values of turbulence (the tail to the right of the frequency distribution of 6-m fog) are observed during the quick dissipation stage of these shallow fog events. Therefore, the mean value of friction velocity for 6- $\mathrm{m}$ fog is slightly larger than the obtained for 15 $\mathrm{m}$ fog (as seen in black solid line of Figure 2a). For deeper fog (more thickness), the frequency distributions are shifted to larger friction velocity values at both sites, as observed in Figure 2a. Note how $n$ is larger for 100-m fog at CIBA (Figure 4) and therefore its associated frequency distribution is widened in comparison with frequency histograms of fog with other thickness, as happened with 6-m fog at CESAR. Besides, although we use 10-min data, $u_{*}$ is a very fluctuating parameter and it is recommended to average its value over larger averaging times (around $1 \mathrm{~h}$ ) for the calculation of continuous fog thickness in an operational use.

\subsubsection{Estimation with buoyancy flux}

On the other hand, and as it will be demonstrated later, fog with a top above a certain height is convectively active and can be considered as well-mixed fog. Therefore, the thickness of this fog is supposed to be more influenced by the buoyancy generated by the fog itself (mainly due to the mixing caused by the radiative cooling at the fog top) than by the wind shear. Thus, some scaling parameter more related to the convection within the fog could become a more appropriate parameter to link with the fog thickness, specially for deep fog. However, for an operational use, the scaling variable should not use information about the height of these buoyancy-related motions (similar to thermals), which is an usual parameter used for scaling convective boundary layers. Therefore, parameters as the convective velocity scale (Stull, 1988) cannot be used since only information about the buoyancy flux can be obtained from a surface sonic anemometer and no information about the height of the thermals (the height of the convective boundary layer or, in this case, the thickness of the fog) will be available. Hence, buoyancy flux values $\left(\overline{w^{\prime} \theta_{v}^{\prime}}\right)$ have been linked to their associated fog thickness. Note that $\overline{w^{\prime} \theta_{v}^{\prime}}$ is calculated from vertical velocity and temperature measurements from a sonic anemometer (which is indeed the virtual temperature, since it is calculated from the density of the air).

Figures $5 \mathrm{a}$ and $\mathrm{b}$ shows the relation between the buoyancy flux and fog thickness at CESAR and CIBA respectively, calculated following the same procedure as with $u_{*}$ in Figure 2. However, in this case the frequency distributions for this variable for each fog thickness (as in Figures 3 and 4, but for $\overline{w^{\prime} \theta_{v}^{\prime}}$ ) show a more asymmetric distribution and more dispersed to extreme values (not shown). Therefore, the use of mean values is not appropriate and median values for each fog thickness have been used to plot the curves shown in Figure 5 (mean values differ significantly from median values in this case and the linear regression is worse). The horizontal errors bars range from percentile 25 to percentile 75 , indicating the position of the central $50 \%$ of the data. These error bars are significantly larger than in the case of friction velocity (Figure 2), even when standard deviations (which include approximately the $67 \%$ of the data with respect to the mean) are shown in Figure 2.

Small values of buoyancy flux (and mainly negative) are associated with shallow fog (Figure 5), related to the weak convection and to the stable conditions within it. Therefore, it is difficult to associate $\overline{w^{\prime} \theta_{v}^{\prime}}$ values with fog thickness of shallow fog. However, it should be noted that the most negative buoyancy flux is found for fog of around 50-m depth at both sites. The explanation for this issue is challenging and it could be related to the fact that most of these fog events (around 50-m fog) are in their initial stage and the negative buoyant motions from the fog-top predominate over positive motions. This issue could also be related to the fact that 50-m fog (approximately) is associated with larger turbulence intensity than shallower fog, as observed in Figure 2. Thus, this turbulence could help to the enhancement of the negative buoyancy flux. However, for deeper, more mixed and mature fog, this descending motions do not seem to predominate but positive ones. This fact seems to indicate that the cooling at the fog top is more important during the development of the fog than during the mature stage, when the buoyancy flux has a wider range of values and more shifted to positive (ascending) ones. Besides, many of these deep fog events are usually persistent during daytime and their larger and positive values of $\overline{w^{\prime} \theta_{v}^{\prime}}$ are also associated with the heating of the surface caused by the fraction of the solar radiation able to cross the fog layer and heat the ground.

Nevertheless, a near-linear relation is found for deep fog (Eq. 4 at CESAR and Eq. 5 at CIBA and red text in Figure 5). Two slopes can be distinguished at CESAR: the first one has been calculated using mean values of $\overline{w^{\prime} \theta_{v}^{\prime}}$ between $55-\mathrm{m}, 105-\mathrm{m}$ and $170-\mathrm{m}$ fog while the second one has been calculated with 170-m and 200$\mathrm{m} \mathrm{fog}(\mathrm{Eq} .4)$. It is somehow logical that the slope of the line linking the upper points (170-m and 200-m fog) is lower, since the fog top is further from the ground and variations in the buoyancy flux at surface are somehow 
less linked to the conditions at that heights. At CIBA, only a linear regression (Eq. 5) is calculated (using 50$\mathrm{m}, 70-\mathrm{m}$ and $100-\mathrm{m}$ fog), due to the lack of data above $100 \mathrm{~m}$.

Therefore, for fog exceeding a height threshold $(\sim 50$ $\mathrm{m})$, the following equations are proposed. At CESAR, if $u_{*} \geq 0.061 \mathrm{~m} \mathrm{~s}^{-1}$ ( 55-m fog from Eq. 2$)$, then

$$
Z_{f-t}=\left\{\begin{array}{ccc}
64419 \overline{w^{\prime} \theta_{v}^{\prime}}+135 & \text { if } & \overline{w^{\prime} \theta_{v}^{\prime}} \leq 5 \times 10^{-4} \mathrm{Kms}^{-1} \\
6617 \overline{w^{\prime} \theta_{v}^{\prime}}+166 & \text { if } & \overline{w^{\prime} \theta_{v}^{\prime}}>5 \times 10^{-4} \mathrm{Kms}^{-1} .
\end{array}\right.
$$

At CIBA, if $u_{*} \geq 0.077 \mathrm{~m} \mathrm{~s}^{-1}(\sim 50-\mathrm{m}$ fog from Eq. 3), then

$$
Z_{f-t}=14360 \overline{w^{\prime} \theta_{v}^{\prime}}+66 .
$$

For fog with $u_{*}<0.061 \mathrm{~m} \mathrm{~s}^{-1}$ and $u_{*}<0.077 \mathrm{~m}$ $\mathrm{s}^{-1}$ at CESAR and CIBA respectively, Eq. 2 and Eq. 3 should be used, since they will be shallow fog with no substantial buoyancy fluxes. Note that $Z_{f-t}$ is obtained in meters if $\overline{w^{\prime} \theta_{v}^{\prime}}$ is provided in $\mathrm{K} \mathrm{m} \mathrm{s}^{-1}$.

In any case, in this case, the linear regression between $\overline{w^{\prime} \theta_{v}^{\prime}}$ and $Z_{f-t}$ is statistically not significant with a confidence level of $95 \%$, mainly due to the few points used to calculate it. Besides, this variable is highly oscillating (more than friction velocity) and an operational use of these equations for the estimation of fog thickness could be less appropriate than using $u_{*}$ alone. $R^{2}$ values are lower than those for the friction velocity and the differences between sites are larger. In addition, the range of the buoyancy flux values varies from negative to positive values, and therefore, neither mean values nor absolute values can be used, since the positive buoyancy fluxes are usually larger than the negative ones.

In brief, the statistics presented in this section suggests the possibility of using data from sonic anemometers (using $u_{*}$ or using $u_{*}$ for shallow fog and $\overline{w^{\prime} \theta_{v}^{\prime}}$ for deep fog above certain threshold) deployed at surface to provide near-real-time estimations of fog thickness (fog-top height). This simple and clear method opens a new (as far as the authors know) manner of estimation of fog-top height with cheaper instruments than usually used. An evaluation of these methods during a representative case study at CESAR is presented in Section 3.3.

Nevertheless, further calibrations are required at other sites to detect site and instrument dependences. For example, although both sites are relatively flat, lo$\mathrm{cal} / \mathrm{mesoscale}$ circulations as low-level jets induced by density currents at CIBA (similar to those of the Ebro Basin (Cuxart and Jiménez, 2012)) or sea-breeze circulations at CESAR (Tijm et al., 1999; Bosveld et al.,
2014; Jiménez et al., 2015) can also influence the evolution of the fog (with a possible enhancement of the vertical growing or favouring the dissipation).

\subsection{Fog thickness estimation through temperature con- vergence (TC method)}

The turbulent mixing within fog causes the homogenization of the layer where the fog is present. The main mechanism proposed in the literature for such turbulent mixing is the radiative cooling at the top of the fog (Nakanishi, 2000; Porson et al., 2011; Price, 2011), causing denser bubbles of air to fall and mix the fog layer. However, the heating of the lower levels by condensation processes, heat fluxes from different surfaces and intermittent turbulence (e.g. gravity waves breaking (Duynkerke, 1991)) can also be involved. The mixing causes the convergence of temperatures at different heights to approximately the same value. Thus, many studies evaluate the fog thickness through the vertical profile of temperature (e.g., Koračin et al., 2001; Liu et al., 2011; Boers et al., 2013; Bari et al., 2015), estimating its presence in the layer where the thermal profile is near neutral or unstable or through the detection of the capping inversion. Although this method (hereinafter temperature convergence method or TC method) has less applicability than the turbulent methods presented in the previous section, it is commonly used in sites with availability of temperature measurements at different heights or with atmospheric soundings (ideally at short time intervals within the fog cycle, as usual in field campaigns).

However, the temperature convergence is not observed in all fog events and some of them remain with stable stratification during an important part of their fog cycle or even for the whole life of the fog. Therefore, an evaluation of the real applicability or skill of this method should be done. Price (2011) detected 18 fog events with temperature convergence from a total of 38 cases. He suggested that the non-converging fog events were shallow ones, but he could not test the theory due to the unavailability of real fog thickness data.

In this section, we compare real fog thickness (obtained with visibility measurements at different heights) with the estimated thickness from temperature measurements. That is, for the estimated fog thickness we consider the fog to be present at a certain height when the difference in potential temperature with the surface level $(2 \mathrm{~m} \mathrm{agl})$ is less than $1.2{ }^{\circ} \mathrm{C}\left(\left|\theta_{2 m}-\theta_{z}\right|=|\Delta \theta|<1.2^{\circ} \mathrm{C}\right)$, where the subscript $z$ indicates the height with available measurements. Thus, we estimate the fog thickness to be the maximum height where this condition is fulfilled. With the use of the potential temperature 
we avoid height-related differences. One can consider that the use of saturated virtual potential temperature is more appropriate, since it includes the effect of the water vapour and liquid water content on the temperature. However, we detected non-substantial differences between using potential temperature and saturated virtual potential temperature (not shown). Therefore, we focus on the use of potential temperature, since only temperature measurements are needed for its calculation, while humidity and LWC information (for example from visibility) are required to compute saturated virtual potential temperature. Thus, this method would lose applicability if saturated virtual potential temperature was used.

A potential temperature difference $(|\Delta \theta|)$ of $1.2^{\circ} \mathrm{C}$ has been selected to determine fog presence since it is the value that offers the best estimations of fog-top height (Table I). Instrument-related uncertainty of temperature measurements is $0.3{ }^{\circ} \mathrm{C}$, therefore, the uncertainty between two temperature measurements is $0.6{ }^{\circ} \mathrm{C}$. However, with a $|\Delta \theta|=1.2^{\circ} \mathrm{C}$ we allow for small differences in temperature between layers and small differences caused by humidity and water content of the air at different heights. This strategy was also followed by Price (2011), who allowed for a difference in temperature between fog layers of $0.8{ }^{\circ} \mathrm{C}$. In any case, several tests were performed (Table II) varying this value and the best results were obtained for $|\Delta \theta|=1$ or $1.2{ }^{\circ} \mathrm{C}$. Although some improvements are observed using other thresholds for certain fog thickness estimations, it is always at the expense of a worsening of the results for other fog thickness, while on average $|\Delta \theta|=1.2^{\circ} \mathrm{C}$ offers the best hit rate for all fog thickness $(69.8 \%$ of correctly estimated fog thickness) and better values than $|\Delta \theta|=1{ }^{\circ} \mathrm{C}$ for deeper fog (see Table II).

Focusing on $|\Delta \theta|=1.2^{\circ} \mathrm{C}$, percentages of success for each fog thickness have been calculated after the comparison of real fog thickness and estimated fog thickness through the temperature convergence method (Figure 6). That is, we evaluate the percentage of times that we are correctly estimating the fog thickness by using only potential temperature at different heights. 6-m fog was the most predominant, with a total of 1408 data. This evaluation has not been performed at CIBA due to the differences in heights between visibility sensors and thermometers (see Figure 1).

Figure 6 shows how with this method, the fog-top height of $89.9 \%$ of $6-\mathrm{m}$ fog is well estimated, and only the remaining percentage is overestimated. This high value of success is determined by the fact that this is the lowest considered level. 6-m fog is associated with strong surface-based thermal inversions and the poten- tial temperature at $10 \mathrm{~m}$ agl is considerably higher than at $2 \mathrm{~m}$ agl. Hence, the method considers no-well mixed fog at $10 \mathrm{~m}$ agl and estimates the fog to be between the first level $(2 \mathrm{~m})$ and the second one $(10 \mathrm{~m})$, but not above this (i.e., $6 \pm 4 \mathrm{~m}$ ), since it considers that the fog is not established at the second level $(10 \mathrm{~m})$. However, the percentage of success for $15-\mathrm{m}$ fog is quite low $(8.5 \%)$, with an underestimation of $86.2 \%$ of fogtop height. That is, estimated thickness for $15-\mathrm{m}$ fog is almost always underestimated, since the potential temperatures at the first and the second level do not converge to approximately the same value (less than $1.2^{\circ} \mathrm{C}$ of difference). The same occurs for $30-\mathrm{m}$ fog, although improving slightly the percentage of success $(18.5 \%)$. However, for deeper fog, the percentage of success of correct estimations improves considerably, with a maximum of $82.9 \%$ of well estimated fog thickness for 140$\mathrm{m}$ fog. That is, temperature convergence does not occur for shallow fog, which are linked to strong thermal inversions and low levels of turbulence and the TC method is not valid.

However, the temperature convergence at the levels where the fog is established is observed for deeper fog, maintaining a considerable difference of temperature with the immediately upper level where the fog is not present. Nevertheless, a decrease in the hit $(54.9 \%)$ is observed for 200-m fog, with an underestimation of $45.1 \%$ of the cases. That is, the potential temperature at $200-\mathrm{m}$ does not converge to the $2 \mathrm{~m}$ value in all the cases when the fog is observed at the $200 \mathrm{~m}$ level. This result suggests that the upper layer of this thick fog is somehow decoupled from the conditions at lower layers.

Figure 7 shows the dispersion plot for the values of $\Delta \theta$ versus $u_{*}$ for observed $200-\mathrm{m}$ fog. Blue points indicate the cases associated with a correctly estimation of fog thickness with the TC method $\left(|\Delta \theta|<1.2^{\circ} \mathrm{C}\right.$ or $\Delta \theta>-1.2^{\circ} \mathrm{C}$ ), while red points show the cases when the TC method underestimate the fog thickness due to $|\Delta \theta|>1.2^{\circ} \mathrm{C}$ (or $\Delta \theta<-1.2^{\circ} \mathrm{C}$ ). In the latter cases, the differences in temperature between $200 \mathrm{~m}$ agl and $2 \mathrm{~m}$ agl are large and negative, or in other words, the thermal inversion is not broken up to the level of $200 \mathrm{~m} \mathrm{agl}$, even when the fog is present there. These cases are associated with less surface turbulence $\left(u_{*}\right)$ than those when the $200-\mathrm{m}$ fog is well estimated (blue points). The mean friction velocity for the correctly estimated $200-\mathrm{m}$ fog is $0.17 \mathrm{~m} \mathrm{~s}^{-1}$, while it is $0.13 \mathrm{~m} \mathrm{~s}^{-1}$ for the incorrectly estimated ones (Figure 7).

In the underestimated cases (red points in Figure 7), the visibility at $200 \mathrm{~m} \mathrm{agl}$ is higher than at $2 \mathrm{~m}$ agl (not shown). That is, although the visibility is $<1000 \mathrm{~m}$, the 
reduction in visibility is not as large as at lower levels and the fog is less dense at the upper layers than below. However, for the correctly-estimated cases (blue points in Figure 7), the visibility is always lower at the fog top than at lower levels, as a result of the lower temperature corresponding to that height (in absolute values), leading to more condensation and thus, more LWC.

Figure 8 shows a conceptual picture of types of radiation fog according to the thermal profile and analyses performed in previous paragraphs. The first one corresponds to shallow fog (type A), usually associated to surface-based thermal inversions, when the mean $u_{*}$ is relatively low $\left(\sim 0.05 \mathrm{~m} \mathrm{~s}^{-1}\right)$ and not large enough to cause the homogenization of the fog layer, leading to a sub-adiabatic (stable) thermal profile. The other two cases correspond to deeper fog ( $200 \mathrm{~m}$ depth), but they differ in the mean $u_{*}$ measured at surface. The nonwell-mixed deep fog (type B) are characterised by mean $u_{*}$ values of around $0.13 \mathrm{~m} \mathrm{~s}^{-1}$. In these cases, the fog is observed at the higher level $(200 \mathrm{~m})$, where the visibility is lower than $1000 \mathrm{~m}$ but larger than at lower layers. However, turbulent values are not strong enough to mix the higher fog-layer and the stable thermal inversion is still present at these levels. Therefore, the temperature is larger at the top and the LWC is usually lower than at lower levels. However, during well-mixed deep fog (type $\mathrm{C}$ ), the turbulent values measured at surface are relatively larger $\left(\sim 0.17 \mathrm{~m} \mathrm{~s}^{-1}\right)$, leading to an effective homogenisation of the fog layer even at the highest levels. Therefore, the temperature at the highest levels is lower and the LWC is higher, associated with more condensation.

\subsection{Evaluation of a case study at CESAR}

An analysis of observed and estimated fog thickness during a long-lasting fog event at CESAR is presented in this section. The case study corresponds to the fog formed during the afternoon of 19 November 2011 at CESAR and lasting until midday of 22 November 2011. This fog event has been chosen among all available cases because it is a long case with a gradual formation (dissipation) of the fog, slowly increasing (decreasing) its thickness and it also has a long mature stage of more than 24 hours. All these reasons make this case to be very appropriate to check the performance of the estimation of fog thickness through surface turbulent measurements $\left(u_{*}\right.$ and $\left.\overline{w^{\prime} \theta_{v}^{\prime}}\right)$ and from temperature measured at different heights (TC method or $|\Delta \theta|$ ). Note that this event was previously removed from the dataset used to obtain the results shown in the previous section in order to perform an independent verification of the skill of these methods.
Figure 9a shows the comparison between observed real thickness (from visibility measurements at different heights, black line) and the estimated ones using the TC method (red dotted line), $u_{*}$ (blue line, Eq. 2), and a combination of $u_{*}$ for shallow fog and $\overline{w^{\prime} \theta_{v}^{\prime}}$ for deeper fog (green dotted line, Eq. 2 and Eq. 4). In the latter case, $u_{*}$ and Eq. 2 have been used when $u_{*}<0.061 \mathrm{~m}$ $\mathrm{s}^{-1}$ (corresponding to fog of approximately less than 50 $\mathrm{m}$ depth), while $\overline{w^{\prime} \theta_{v}^{\prime}}$ and Eq. 4 have been used when the friction velocity is above this threshold, using two different slopes depending on the buoyancy flux threshold indicated in Eq. 4.

Regarding the $u_{*}$-based estimation (blue line in Figure 9a) using the equation presented in Figure 2a (Eq. 2 ), the general evolution of fog thickness is well estimated, with a relatively good estimation when the fog is growing or dissipating (from above), following the behaviour of observed $u_{*}$ (Figure 9c). However, during the mature stage (from day 20 at 12:00 UTC to day 21 at 18:00 UTC approximately), this method tends to underestimate the fog thickness, which is most of the time constant $(170 \mathrm{~m})$ with some periods when the fogtop height is oscillating between 170 and $200 \mathrm{~m}$ agl (or more). In any case, this underestimation is sometimes within the uncertainty of observed fog events $(170 \pm 30$ $\mathrm{m})$. Besides this, the underestimation is quite constant, which suggest that correction factors could be added for fog of certain thickness (e.g. adding $+40 \mathrm{~m}$ to the result obtained for fog thicker than approximately $100 \mathrm{~m}$ ).

Green dotted line shows the estimation of fog thickness using $u_{*}$ for non-well mixed fog and $\overline{w^{\prime} \theta_{v}^{\prime}}$ for convective fog or fog exceeding a critical value of $u_{*}$, as commented before. Hence, the green dotted line coincides with the blue line for shallow fog. However, for deeper fog, there is normally an overestimation, especially around midday, when the surface buoyancy flux is directly influenced by the heating of the ground caused by the part of the short wave radiation able to cross over the fog layer. However, this increase in the buoyancy flux (Figure 9d) is not traduced in a direct increase in fog thickness in the reality and in this particular case the $\overline{w^{\prime} \theta_{v}^{\prime}}-Z_{f-t}$ relation does not work satisfactorily during the daytime. However, during the mature stage and in nighttime conditions, the method provides a quite satisfactory estimation of the fog-top height (see for example from 18:00 UTC of day 20 to 06:00 UTC of day 21).

With respect to the temperature-based estimation (TC method) of fog thickness (red dotted line in Figure 9a), the results are in general quite satisfactory, although the method underestimates the fog thickness when the fog is shallow, especially during the formation stage, when 
the vertical temperature profile is still stable and the inversion is not broken by the turbulent mixing within the fog (Figure 9b). There is also an underestimation when the fog is fluctuating between two different levels, as happened for example around 06:00 UTC of day 20, when the fog thickness was oscillating between 55 and $105 \mathrm{~m}$ depth. In this cases, it seems that the fog is not well established at the higher level and the temperature does not converge to the same value at that level. The same happens in the mature stage during the periods when the fog top is oscillating between 170 and $200 \mathrm{~m}$ agl (or more) (e.g. around 12:00 UTC of day 21). In these cases, the temperature at the highest level (200 m agl) is almost always considerably higher and it does not decrease to the values of lower layers (see Figure $9 \mathrm{~b}$ ), meaning that although the visibility is less than $1000 \mathrm{~m}$ at $200 \mathrm{~m}$ agl, the upper layer is not completely well homogenised and the potential temperature remains higher, which would correspond to fog of type B in Figure 8.

The evaluation performed for this case study offers similar results than those from the statistical analysis provided in Sections 3.1 and 3.2.

\section{Conclusions}

The problem of having reliable information of fog thickness (fog-top height) is addressed in this study. On the one hand, we use a set of radiation fog events (and cloud base lowering fog events) to correlate surface turbulence with fog thickness at two experimental sites (CESAR and CIBA). Fog thickness follows a linear correlation with surface friction velocity at both sites, with slight differences between sites. Therefore, linear equations are obtained for the estimation of fog-top height through surface friction velocity measurement for each site $\left(Z_{f-t}=1369 u_{*}-28\right.$ at CESAR and $Z_{f-t}=1029$ $u_{*}-30$ at CIBA). These equations show high values of correlation coefficients $\left(\mathrm{R}^{2}=0.974\right.$ and 0.982 respectively). Additionally, we propose the use of the buoyancy flux measured at the surface for convectively active fog (exceeding an $u_{*}$ threshold of approximately $0.07 \mathrm{~m} \mathrm{~s}^{-1}$ ), since fog thickness also shows a significant correlation with this parameter. However, although a linear correlation is obtained, the error bars suggest this parameter to be noisier than $u_{*}$, while it also oscillates from large positive to slightly negative values. In addition, the evaluation of this method for a case study demonstrates how the use of the buoyancy flux usually overestimates the fog thickness during daytime, when the surface heat flux is larger due to the fraction of solar energy able to cross the fog layer.
On the other hand, the estimation of fog thickness through the temperature-convergence method is evaluated at CESAR. This method is based on the turbulent homogenization of well-mixed fog, which makes the potential temperature converge to approximately the same value at the heights where the fog layer is present. Thus, fog-top height is defined as the maximum height (z) where $|\Delta \theta|=\theta_{2 m}-\theta_{z}$ is lower than $1.2^{\circ} \mathrm{C}$. It is shown how this method offers satisfactory results for deep fog ( $100 \mathrm{~m}$ or more). However, the method is unsuccessful for shallow fog, since it is associated with surfacebased thermal inversions and the turbulence within it is not enough to break the stability. On the other hand, it seems that the upper layer in very deep fog $(\sim 200 \mathrm{~m})$ is somehow decoupled from the lower layers in some cases associated with relatively low-moderate values of surface friction velocity $\left(\sim 0.13 \mathrm{~m} \mathrm{~s}^{-1}\right)$. In these cases, visibilities lower than $1000 \mathrm{~m}$ are observed at the top of the fog but the mixing from lower layers is not completely effective.

These results are tested with a long-lasting fog event observed at CESAR. The results suggest how these methods are valid options for estimating fog thickness in near-real time conditions during a complete fog cycle. However, the temperature-convergence method is not valid for shallow fog (especially during growing fog) and it tends to slightly underestimate fog thickness during periods when the fog is deeper. On the other hand, $u_{*}$ is demonstrated as a powerful parameter for the estimation of fog-top height if some corrections are applied during deeper-fog events.

The presented results can be useful when trying to estimate fog thickness with a unique sonic anemometer deployed at surface or a set of thermometers at different heights. However, further calibrations and studies at other sites are required to detect site-dependence and instruments-dependence issues.

\section{Acknowledgements}

This research has been funded by the Spanish Government (MINECO project CGL2012-37416-C04-02 and grant BES-2013 064585). The GR3/14 program (supported by UCM and Banco Santander) has also partially financed this work through the Research Group Micrometeorology and Climate Variability (No. 910437). Part of this work has been completed during a scientific stay of Carlos Román-Cascón in Wageningen University through a WIMEK Research Fellowship. The contribution by G.J. Steeneveld has partly been sponsored by the NWO contract 863.10.010 (Lifting the 


\section{$8 \quad$ References}

Bari, D., Bergot, T., El Khlifi, M., 2015. Numerical study of a coastal fog event over casablanca, morocco. Q. J. R. Meteorol. Soc. 141, 1894-1905.

Beljaars, A. C., Bosveld, F. C., 1997. Cabauw data for the validation of land surface parameterization schemes. J. Clim. 10 (6), 11721193.

Bendix, J., Thies, B., Cermak, J., Nauß, T., 2005. Ground fog detection from space based on modis daytime data-a feasibility study. Weather Forecast. 20 (6), 989-1005.

Bergot, T., Terradellas, E., Cuxart, J., Mira, A., Liechti, O., Mueller, M., Nielsen, N. W., 2007. Intercomparison of single-column numerical models for the prediction of radiation fog. J. Appl. Meteorol. Climatol. 46 (4), 504-521.

Boers, R., Baltink, H. K., Hemink, H., Bosveld, F., Moerman, M., 2013. Ground-based observations and modeling of the visibility and radar reflectivity in a radiation fog layer. J. Atmos. Oceanic Technol. 30 (2), 288-300.

Bosveld, F., Baas, P., Steeneveld, G., Holtslag, A., Angevine, W., Bazile, E., de Bruijn, E., Deacu, D., Edwards, J., Ek, M., et al., 2014. The gabls third intercomparison case for model evaluation, part b: Scm model intercomparison and evaluation. Boundarylayer Meteorol. 152, 157-187.

Brenguier, J.-L., Pawlowska, H., Schüller, L., Preusker, R., Fischer, J., Fouquart, Y., 2000. Radiative properties of boundary layer clouds: Droplet effective radius versus number concentration. J. Atmos. Sci. 57 (6), 803-821.

Cermak, J., Bendix, J., 2008. A novel approach to fog/low stratus detection using meteosat 8 data. Atm. Res. 87 (3), 279-292.

Cermak, J., Bendix, J., 2011. Detecting ground fog from space-a microphysics-based approach. Int. J. Remote Sens. 32 (12), 3345 3371.

Cuxart, J., Jiménez, M., 2012. Deep radiation fog in a wide closed valley: study by numerical modeling and remote sensing. Pure Appl. Geophys. 169 (5-6), 911-926.

Cuxart, J., Yagüe, C., Morales, G., Terradellas, E., Orbe, J., Calvo, J., Fernández, A., Soler, M., Infante, C., Buenestado, P., Espinalt, A., Joergensen, H., Rees, J., Vilà, J., Redondo, J., Cantalapiedra, I., Conangla, L., 2000. Stable atmospheric boundary-layer experiment in spain (sables 98): a report. Boundary Layer Meteorol. 96 (3), 337-370.

Dabas, A., Remy, S., Bergot, T., 2012. Use of a sodar to improve the forecast of fogs and low clouds on airports. Pure Appl. Geophys. 169 (5-6), 769-781.

DOC/NOAA, 1995. Surface weather observations and reports, Federal Meteorological Handbook No. 1, 94 pp. Available from Department of Commerce, NOAA, Office of the Federal Coordinator for Meteorological Services and Supporting Research, 8455 Colesville Road, Suite 1500, Silver Spring, MD, 20910.

Dupont, J.-C., Haeffelin, M., Protat, A., Bouniol, D., Boyouk, N., Morille, Y., 2012. Stratus-fog formation and dissipation: a 6-day case study. Boundary Layer Meteorol. 143 (1), 207-225.
Duynkerke, P. G., 1991. Observation of a quasi-periodic oscillation due to gravity waves in a shallow radiation fog. Q. J. R. Meteorol. Soc. 117 (502), 1207-1224.

Ellrod, G. P., 1995. Advances in the detection and analysis of fog at night using goes multispectral infrared imagery. Wea. Forecasting $10(3), 606-619$.

Fabbian, D., de Dear, R., Lellyett, S., 2007. Application of artificial neural network forecasts to predict fog at canberra international airport. Wea. Forecasting 22 (2), 372-381.

Guedalia, D., Bergot, T., 1994. Numerical forecasting of radiation fog. part ii: A comparison of model simulation with several observed fog events. Mon. Weather Rev. 122 (6), 1231-1246.

Gultepe, I., Tardif, R., Michaelides, S., Cermak, J., Bott, A., Bendix, J., Müller, M., Pagowski, M., Hansen, B., Ellrod, G., Jacobs, W., Toth, G., Cober, S., 2007. Fog research: A review of past achievements and future perspectives. Pure Appl. Geophys. 164 (6-7), 1121-1159.

Jiménez, P. A., de Arellano, J. V.-G., Dudhia, J., Bosveld, F. C., 2015. Role of synoptic-and meso-scales on the evolution of the boundary-layer wind profile over a coastal region: the near-coast diurnal acceleration. Meteorol. Atmos. Phys., 1-18.

Koračin, D., Lewis, J., Thompson, W. T., Dorman, C. E., Businger, J. A., 2001. Transition of stratus into fog along the california coast: Observations and modeling. J. Atmos. Sci. 58 (13), 1714-1731.

Liu, D., Yang, J., Niu, S., Li, Z., 2011. On the evolution and structure of a radiation fog event in nanjing. Adv. Atmos. Sci. 28, 223-237.

Menut, L., Mailler, S., Dupont, J.-C., Haeffelin, M., Elias, T., 2014. Predictability of the meteorological conditions favourable to radiative fog formation during the 2011 parisfog campaign. Boundary Layer Meteorol. 150 (2), 277-297.

Nakanishi, M., 2000. Large-eddy simulation of radiation fog. Boundary Layer Meteorol. 94 (3), 461-493.

Porson, A., Price, J., Lock, A., Clark, P., 2011. Radiation fog. part ii: Large-eddy simulations in very stable conditions. Boundary Layer Meteorol. 139 (2), 193-224.

Price, J., 2011. Radiation fog. part i: observations of stability and drop size distributions. Boundary Layer Meteorol. 139 (2), 167-191.

Price, J., Porson, A., Lock, A., 2015. An observational case study of persistent fog and comparison with an ensemble forecast model. Boundary Layer Meteorol. 155 (2), 301-327.

Rémy, S., Bergot, T., 2009. Assessing the impact of observations on a local numerical fog prediction system. Q. J. R. Meteorol. Soc. 135 (642), 1248-1265

Reudenbach, C., Bendix, J., 1998. Experiments with a straightforward model for the spatial forecast of fog/low stratus clearance based on multi-source data. Meteorol. Appl. 5 (3), 205-216.

Román-Cascón, C., Steeneveld, G., Yagüe, C., Sastre, M., Arrillaga, J., Maqueda, G., 2015. Forecasting radiation fog at climatologically contrasting sites: evaluation of statistical methods and wrf. Q. J. R. Meteorol. Soc., in press.

Román-Cascón, C., Yagüe, C., Sastre, M., Maqueda, G., Salamanca, F., Viana, S., 2012. Observations and wrf simulations of fog events at the spanish northern plateau. Adv. Sci. Res. 8 (1), 11-18.

Sastre, M., Yage, C., Román-Cascón, C., Maqueda, G., 2015. Atmospheric boundary-layer evening transitions: A comparison between two different experimental sites. Boundary Layer Meteorol. 157 (3), 375-399.

Shi, C., Wang, L., Zhang, H., Zhang, S., Deng, X., Li, Y., Qiu, M., 2012. Fog simulations based on multi-model system: a feasibility study. Pure Appl. Geophys. 169 (5-6), 941-960.

Steeneveld, G., Ronda, R., Holtslag, A., 2015. The challenge of forecasting the onset and development of radiation fog using mesoscale atmospheric models. Boundary Layer Meteorol. 154 (2), 265-289.

Stolaki, S., Pytharoulis, I., Karacostas, T., 2012. A study of fog characteristics using a coupled wrf-cobel model over thessaloniki air- 
port, greece. Pure Appl. Geophys. 169 (5-6), 961-981.

Tardif, R., Rasmussen, R. M., 2007. Event-based climatology and typology of fog in the new york city region. J. Appl. Meteorol. Climatol. 46 (8), 1141-1168.

Tijm, A., Holtslag, A., Van Delden, A., 1999. Observations and modeling of the sea breeze with the return current. Monthly weather review 127 (5), 625-640.

Van der Velde, I., Steeneveld, G., Wichers Schreur, B., Holtslag, A., 2010. Modeling and forecasting the onset and duration of severe radiation fog under frost conditions. Mon. Weather Rev. 138 (11), 4237-4253

Ye, X., Wu, B., Zhang, H., 2015. The turbulent structure and transport in fog layers observed over the tianjin area. Atm. Res. 153, $217-$ 234.

Yi, L., Zhang, S., Thies, B., Shi, X., Trachte, K., Bendix, J., 2015. Spatio-temporal detection of fog and low stratus top heights over the yellow sea with geostationary satellite data as a precondition for ground fog detectiona feasibility study. Atm. Res. 151, 212223. 


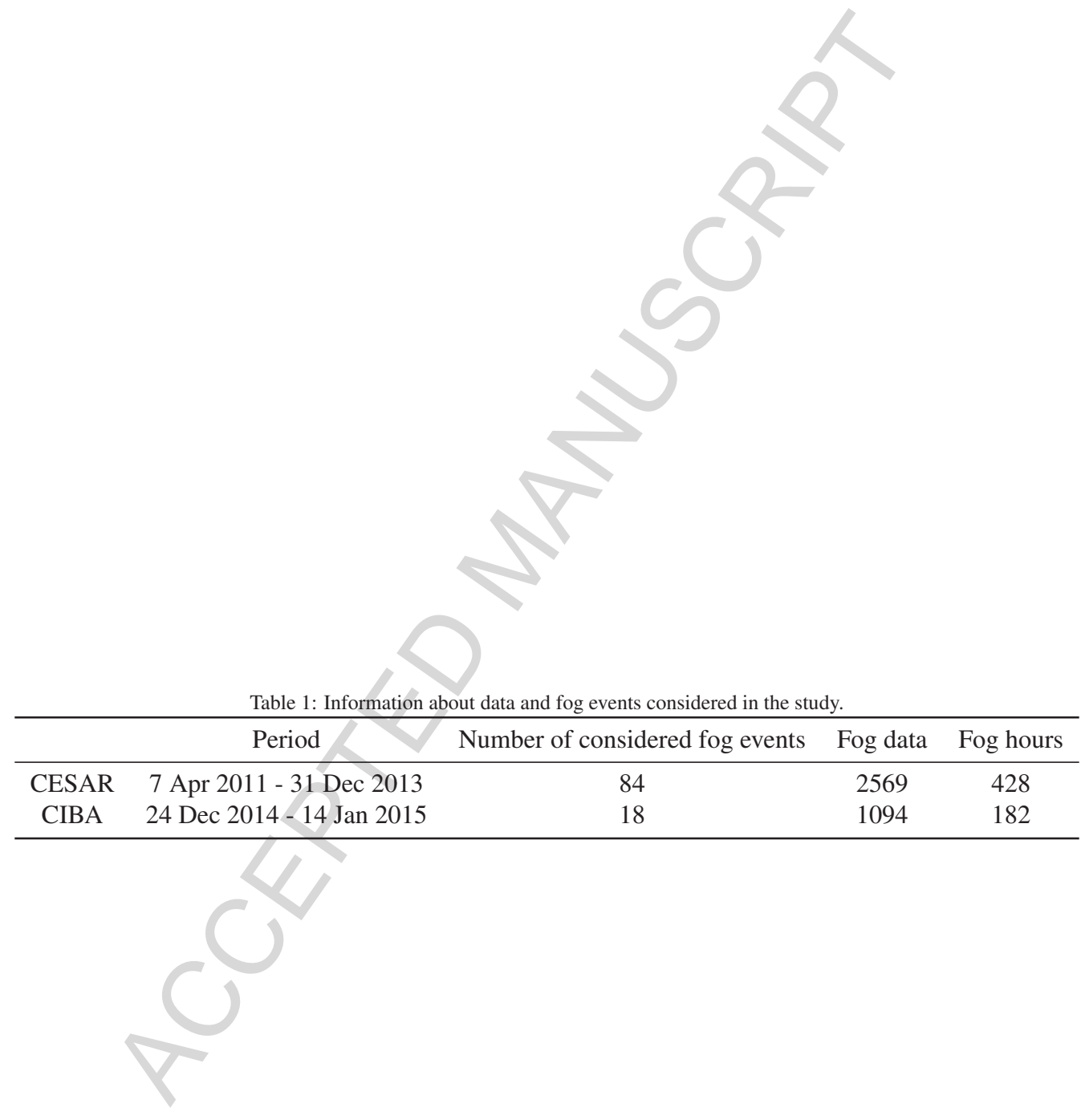


Table 2: Percentage of correctly estimated fog at CESAR using the temperature-convergence (TC) method for several values of differences in potential temperature $(|\Delta \theta|)$ for fog with different thickness and for all fog thickness (last column).

Hit (\%)

\begin{tabular}{ccccccccc}
$|\Delta \theta|\left({ }^{\circ} \mathbf{C}\right)$ & $\mathbf{6 - m}$ fog & $\mathbf{1 5}-\mathbf{m}$ fog & $\mathbf{3 0 - m}$ fog & $\mathbf{5 5}-\mathbf{m}$ fog & $\mathbf{1 0 5}-\mathbf{m}$ fog & $\mathbf{1 7 0}-\mathbf{m}$ fog & $\mathbf{2 0 0 - m}$ fog & All fog \\
\hline 0,6 & 97,7 & 2,4 & 8,9 & 32,9 & 50 & 62,2 & 12,2 & $\mathbf{6 4 , 7}$ \\
0,8 & 96,1 & 4,1 & 12,2 & 39,2 & 58,9 & 68,6 & 33,8 & $\mathbf{6 7 , 3}$ \\
1 & 93,7 & 6,1 & 15,4 & 46,8 & 64,8 & 75,3 & 45,6 & $\mathbf{6 8 , 6}$ \\
$\mathbf{1 , 2}$ & 89,9 & 8,5 & 18,5 & 48,1 & 70 & 82,9 & 54,9 & $\mathbf{6 8 , 6}$ \\
1,4 & 84 & 11,4 & 23,6 & 51,9 & 71,9 & 83,9 & 61,2 & $\mathbf{6 7 , 1}$ \\
1,6 & 75,8 & 14,2 & 26,4 & 54,4 & 71,9 & 84,3 & 64,4 & $\mathbf{6 3 , 6}$ \\
\hline
\end{tabular}




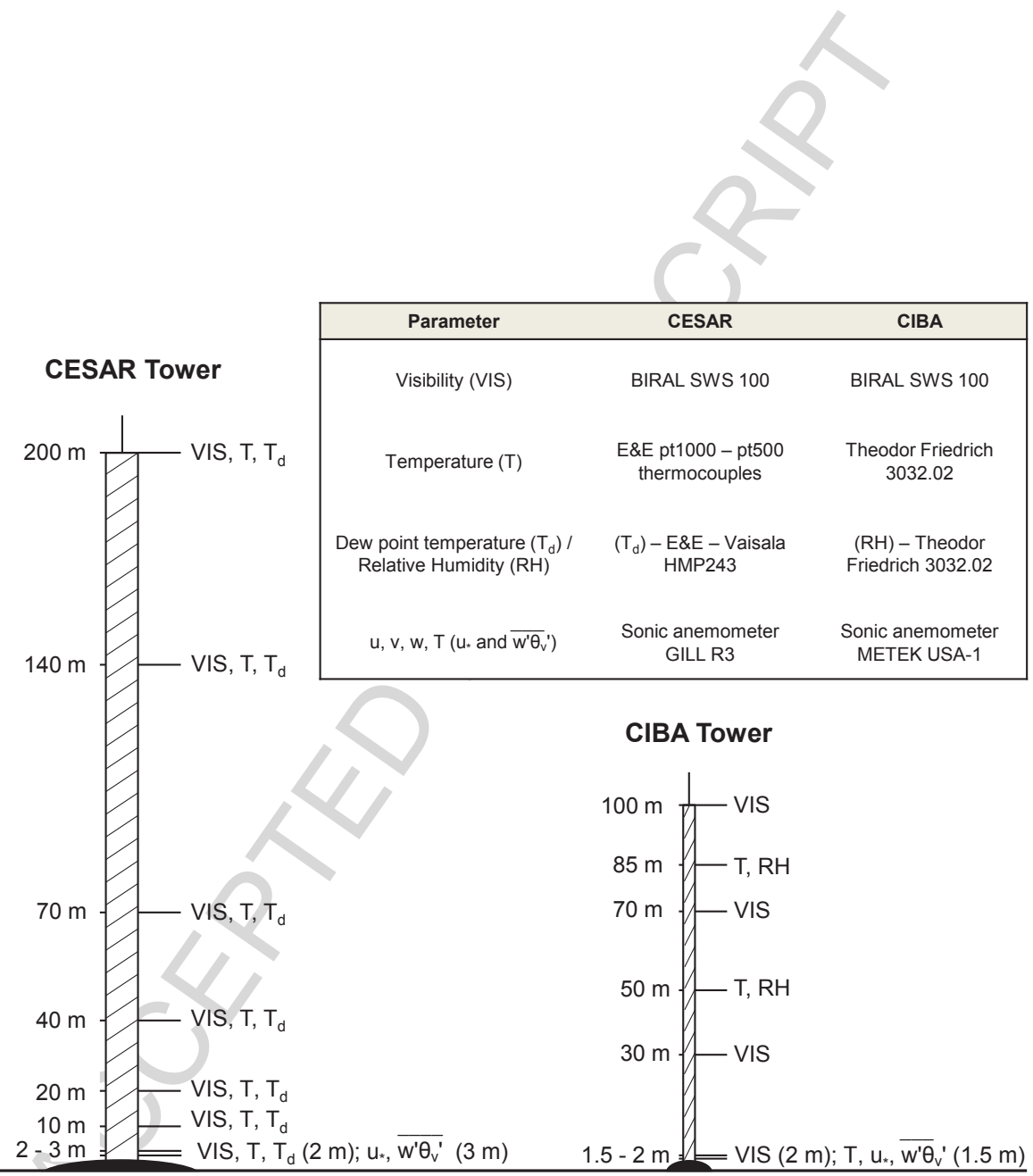

Figure 1: Graphical representation of CESAR and CIBA towers with measurements taken at each height. Information about the instruments is provided in the upper table. 
a)

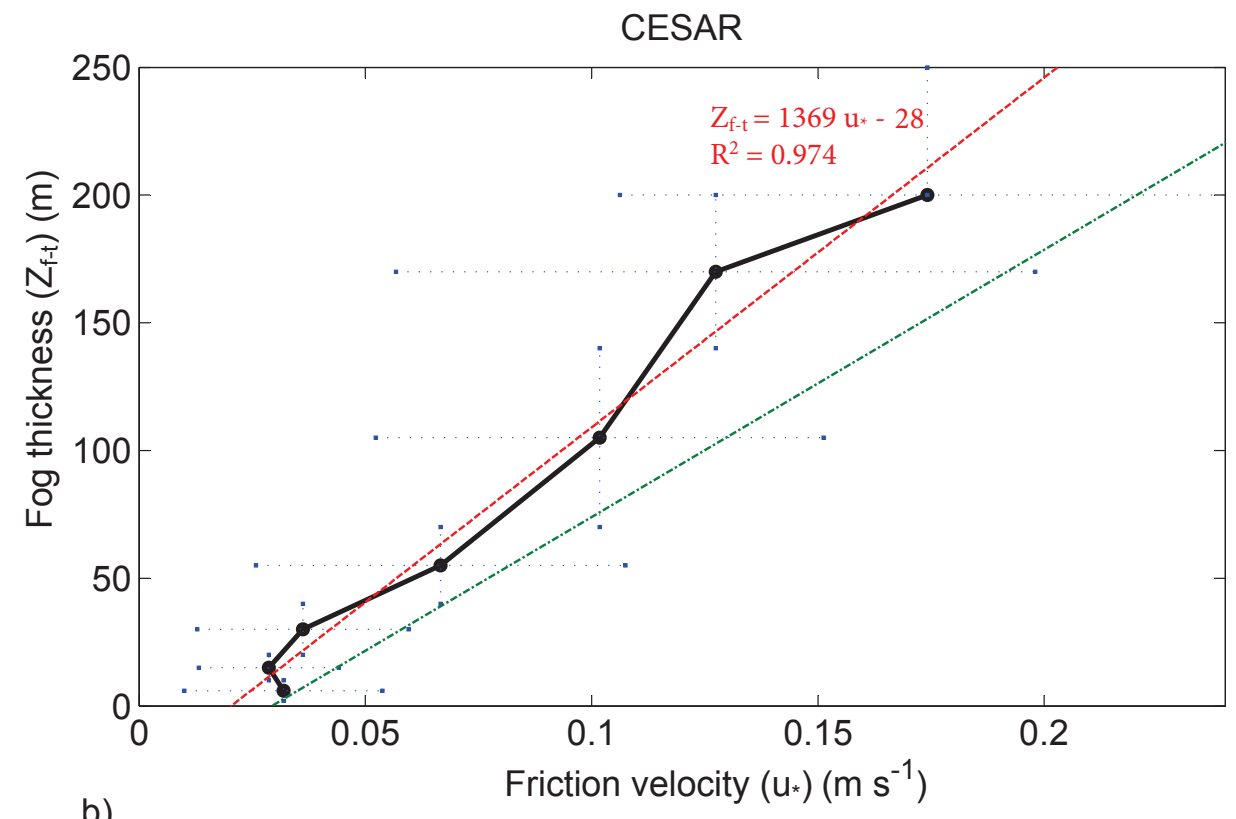

b)

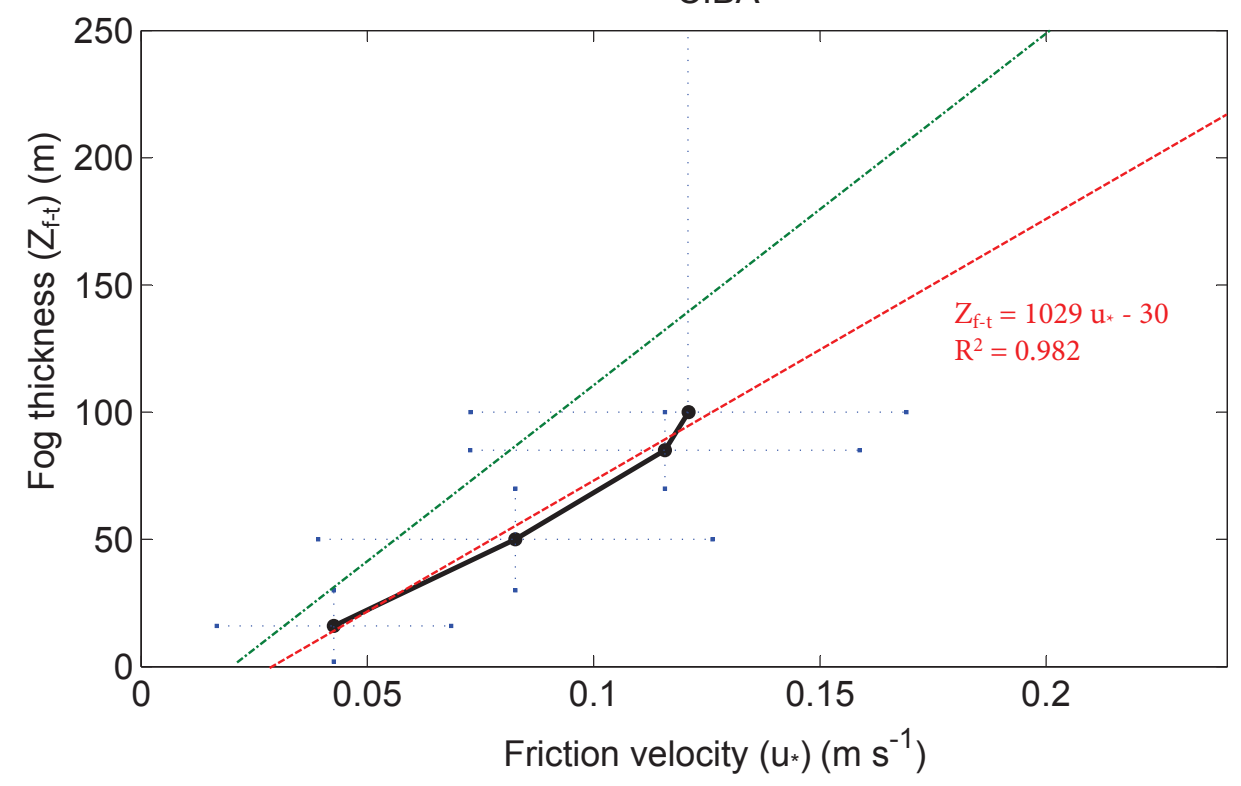

Figure 2: a) CESAR. b) CIBA. Mean friction velocity $\left(u_{*}\right)\left(\mathrm{m} \mathrm{s}^{-1}\right)$ associated to each discrete value of fog thickness (m) (black solid line). The red dotted line represents the linear regression for these points with its equation and $\mathrm{R}^{2}$ in red text. The green dotted-dashed line indicates the linear regression obtained at the other experimental site (e.g. the green line above (CESAR) corresponds to the red line below (at CIBA)). Horizontal dotted lines indicate the error bars of $u_{*}$, determined by the standard deviation of the set of measurements for each fog thickness. Vertical dotted lines indicates the error bars for each fog thickness, determined by the distance between visibilimeters in CESAR (a) and CIBA (b) towers. 

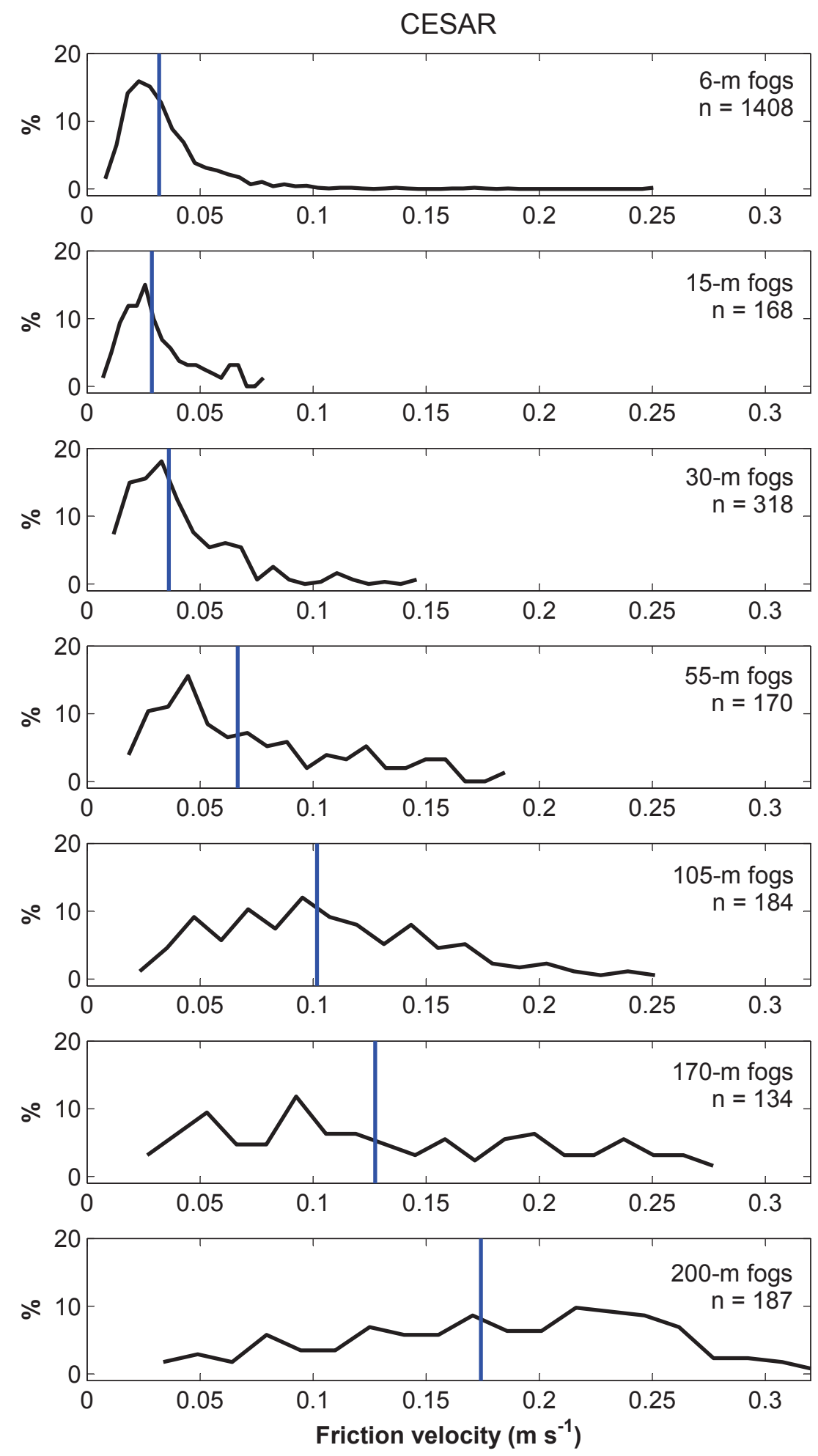

16

Figure 3: CESAR - Frequency distribution plots for friction velocity measurements $\left(\mathrm{m} \mathrm{s}^{-1}\right)$ associated to each fog thickness $(6,15,30,55,105$, $170,200 \mathrm{~m}$-from top to bottom-). The blue vertical line indicates the mean value (used in Figure $2 \mathrm{a}$ in black solid line), while $n$ indicates the number of data for each fog thickness. 

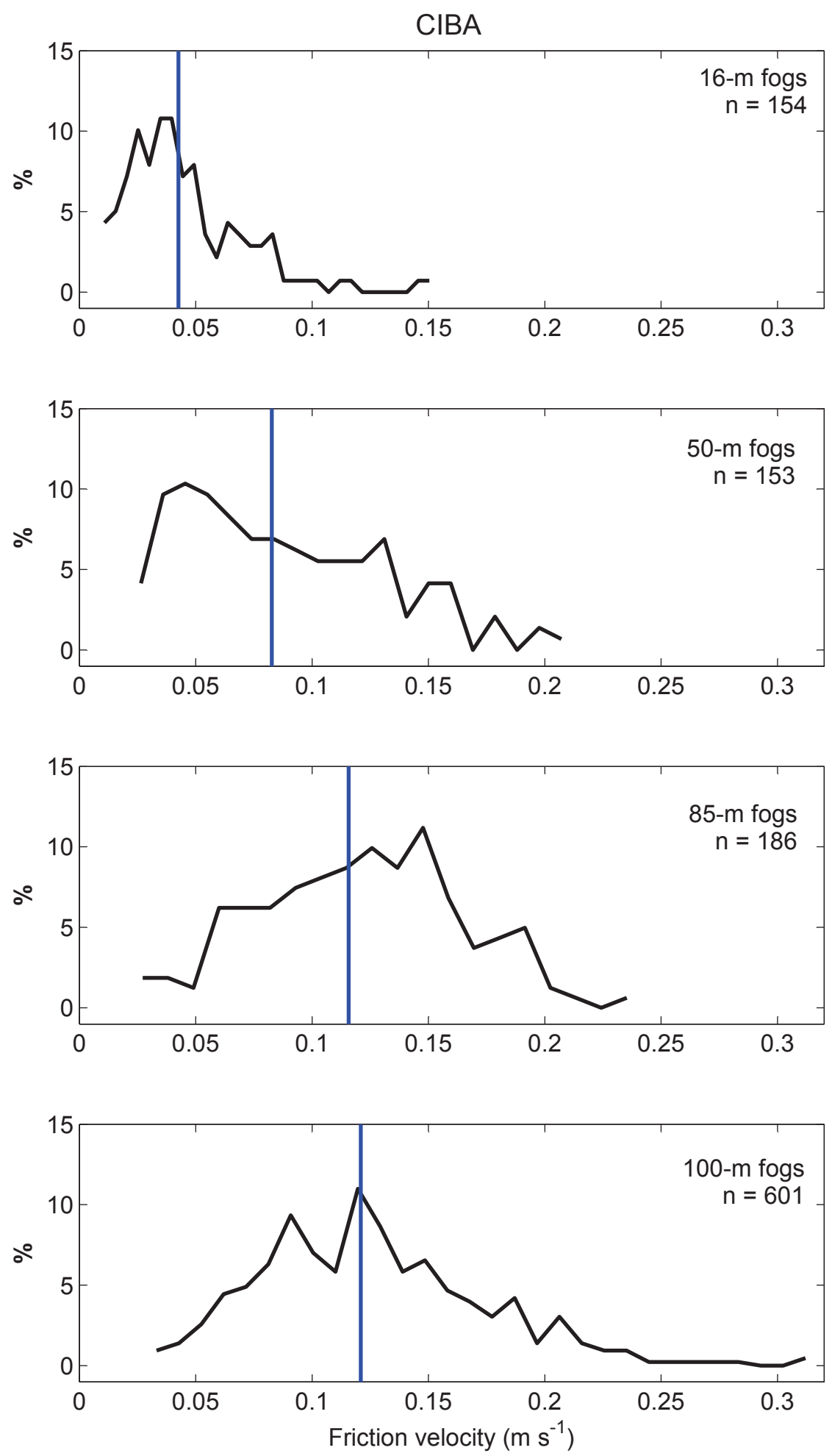

17

Figure 4: CIBA - Frequency distribution plots for friction velocity measurements $\left(\mathrm{m} \mathrm{s}^{-1}\right)$ associated to each fog thickness $(16,50,85,100 \mathrm{~m}$-from top to bottom-). The blue vertical line indicates the mean value (used in Figure $2 \mathrm{~b}$ in black solid line), while $n$ indicates the number of data for each fog thickness. 

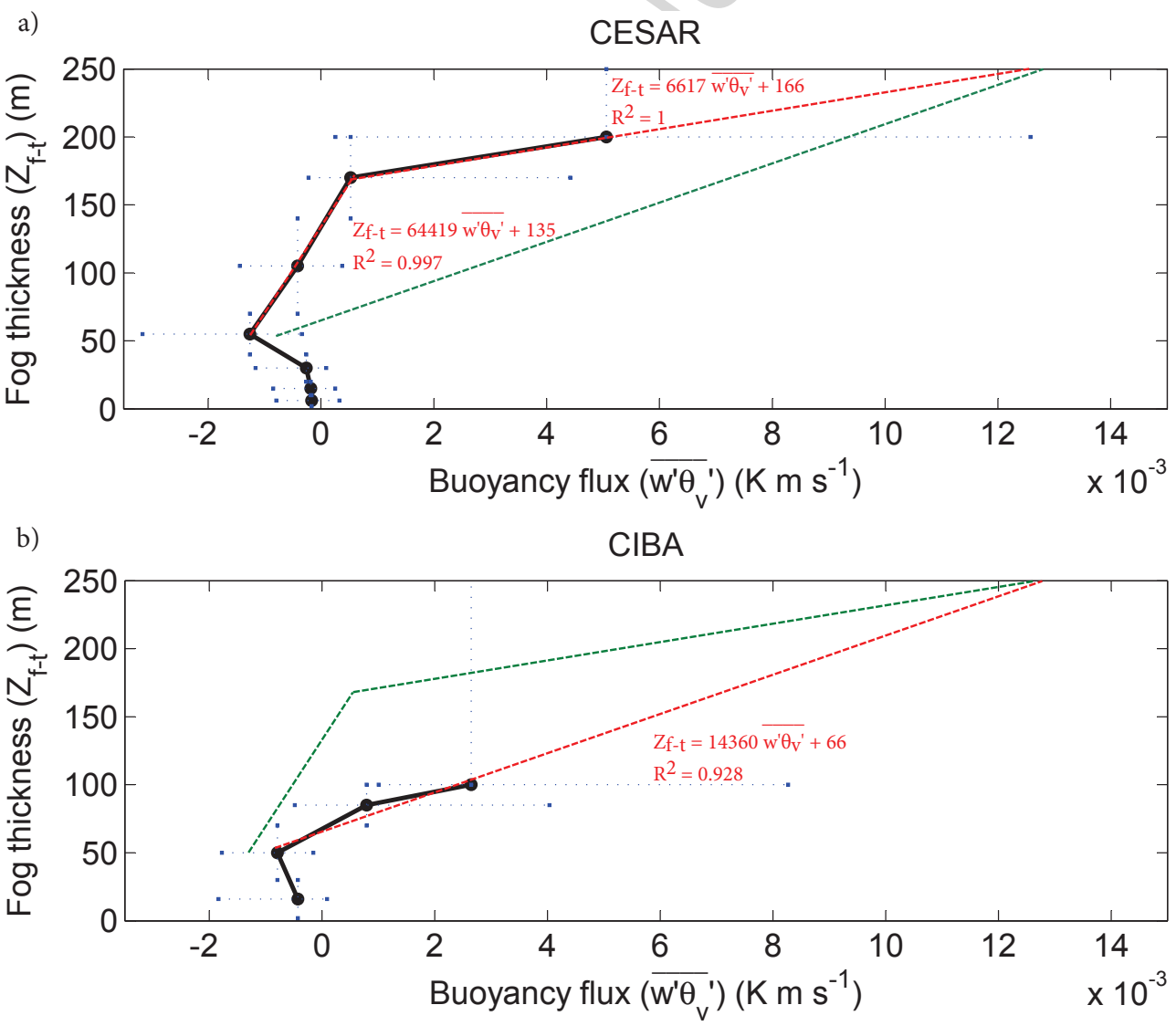

Figure 5: a) CESAR. b) CIBA. Buoyancy flux $\left(\overline{w^{\prime} \theta_{v}^{\prime}}\right)\left(\mathrm{K} \mathrm{m} \mathrm{s}^{-1}\right)$ median values associated to each discrete value of fog thickness (m) (black solid line). Red dashed lines represent the linear regressions for points considering fog thickness higher than 55-m at CESAR and 50-m at CIBA (corresponding to the equations written in red). Horizontal dotted blue lines indicate the error bars of $\overline{w^{\prime} \theta_{v}^{\prime}}$, determined by percentiles 25 and 75 of the set of measurements for each fog thickness. Vertical dotted blue lines indicates the error bars for each fog thickness, determined by the distance between visibilimeters in CESAR (a) and CIBA (b) towers. 

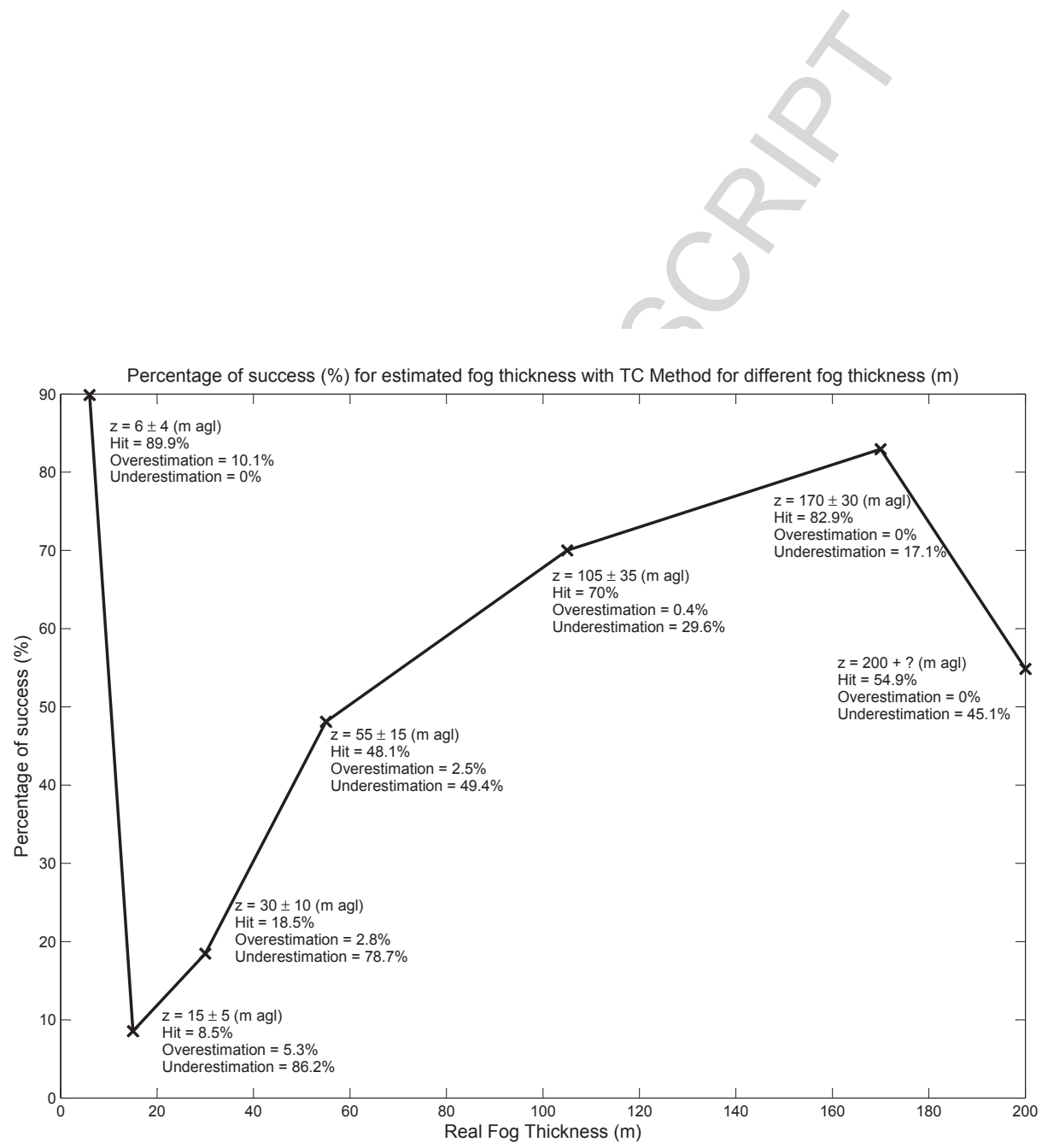

Figure 6: Percentage of success when estimating fog thickness with the temperature-convergence (TC) method for each real observed fog thickness at CESAR. Text around points indicate the percentage of overestimated and underestimated values. 


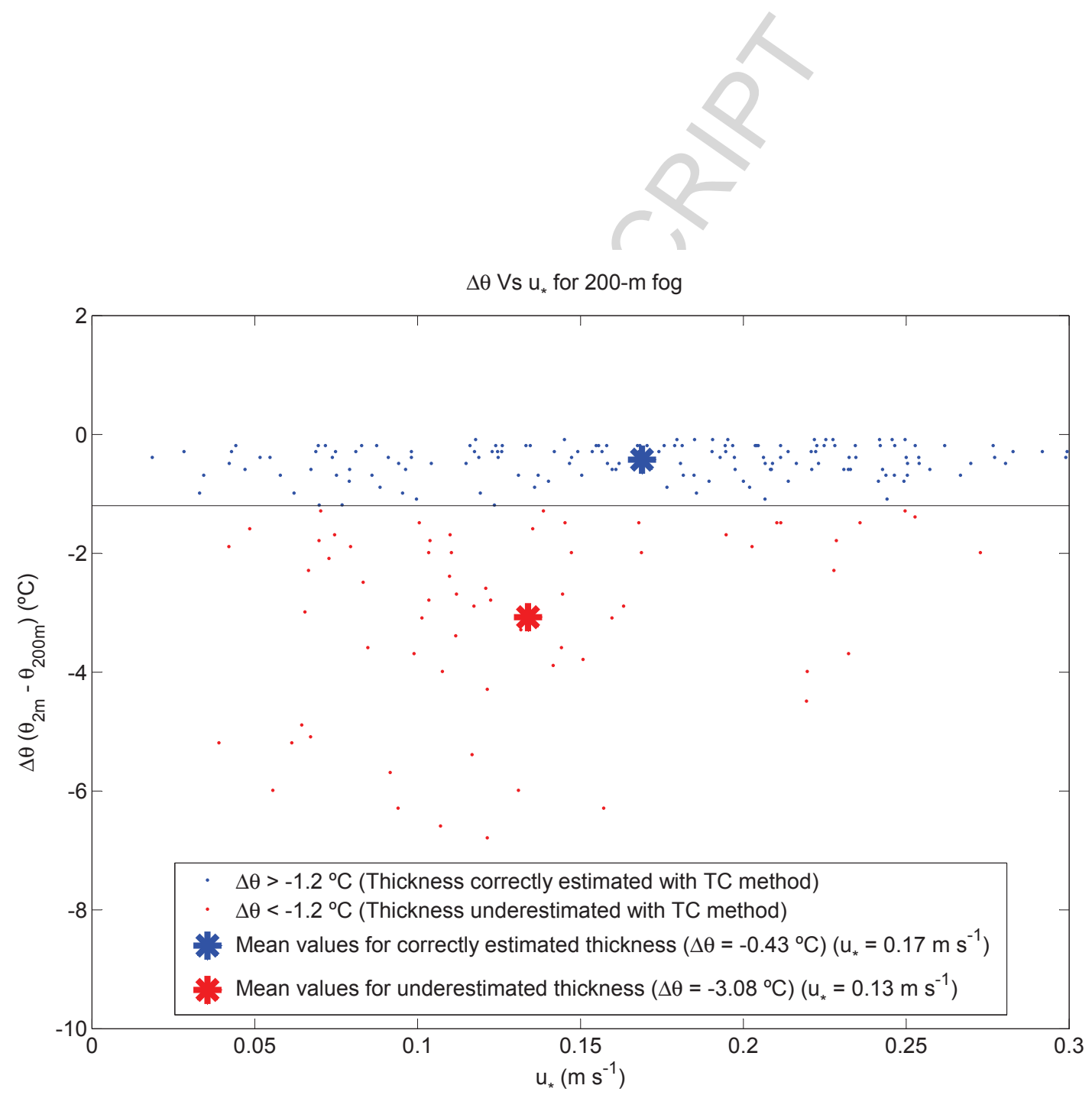

Figure 7: $\Delta \theta\left(\theta_{2 m}-\theta_{200 m}\right)$ versus $u_{*}$ for 200 -m fog. Blue points indicate $\Delta \theta>-1.2{ }^{\circ} \mathrm{C}$ and red points $\Delta \theta<-1.2{ }^{\circ} \mathrm{C}$. The stars with the respective colors indicate their mean values for $\Delta \theta$ and $u_{*}$. 


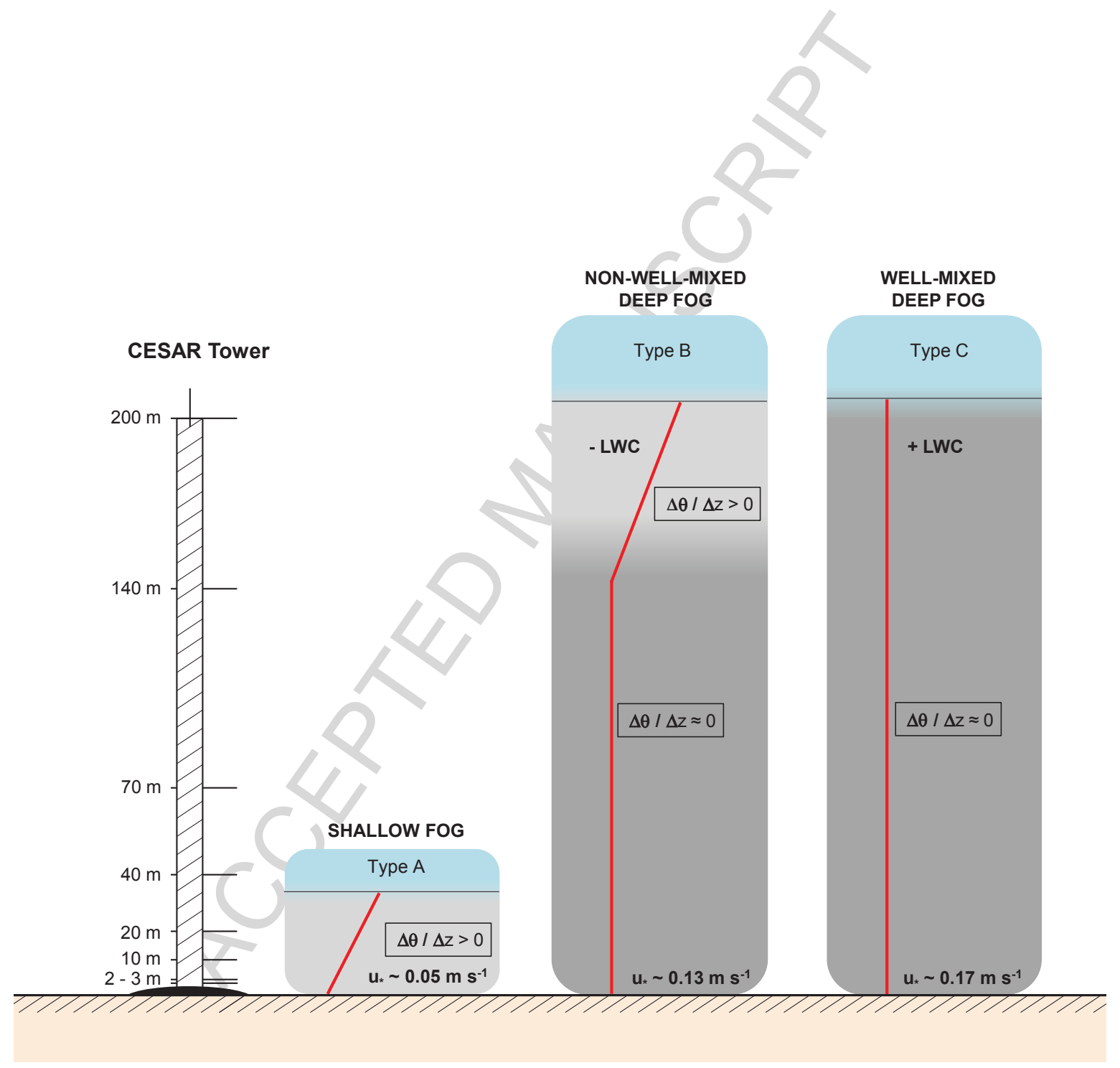

Figure 8: Conceptual picture of types of radiation fog according to their thermal vertical profile and results of Section 3.2. 

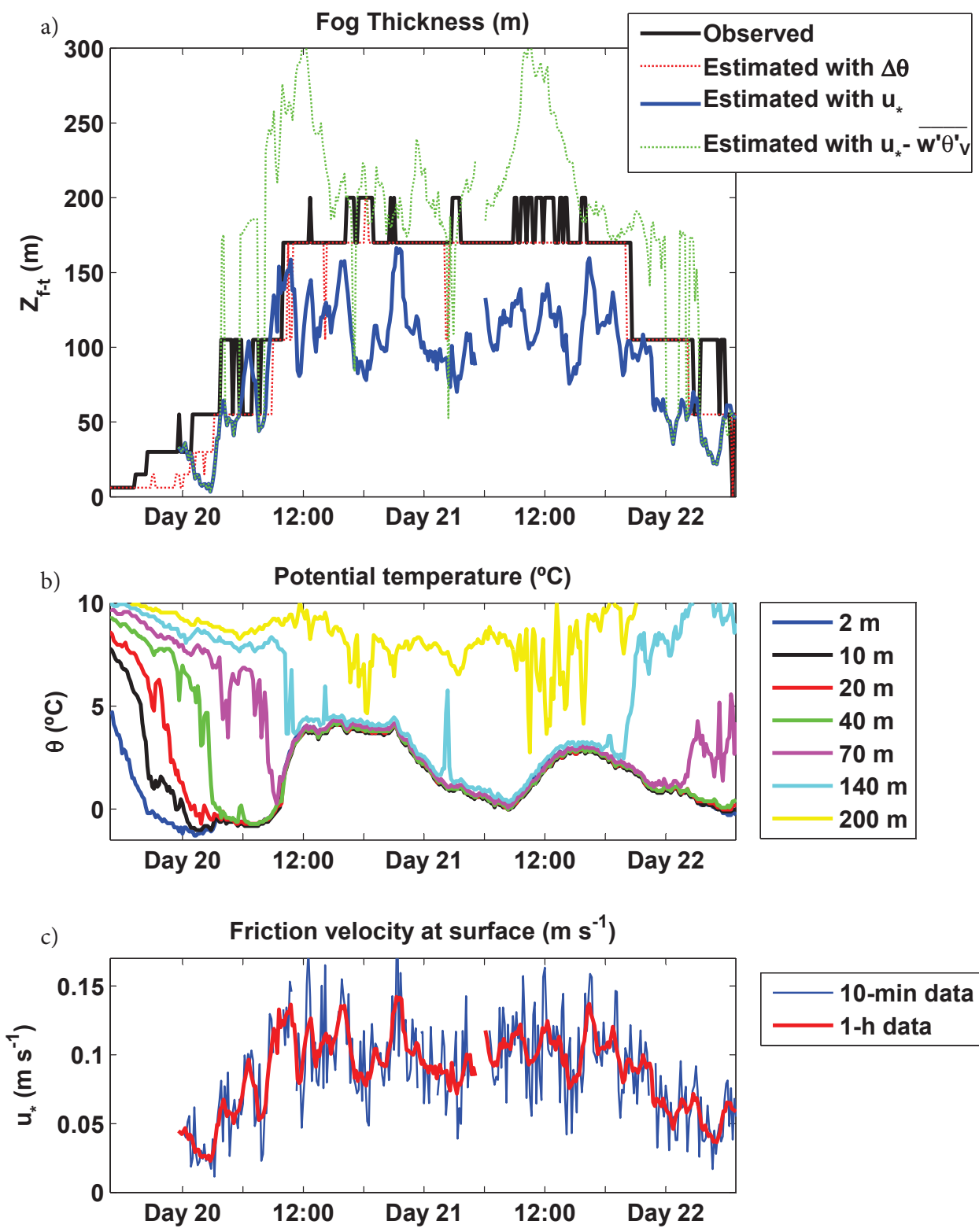

d)

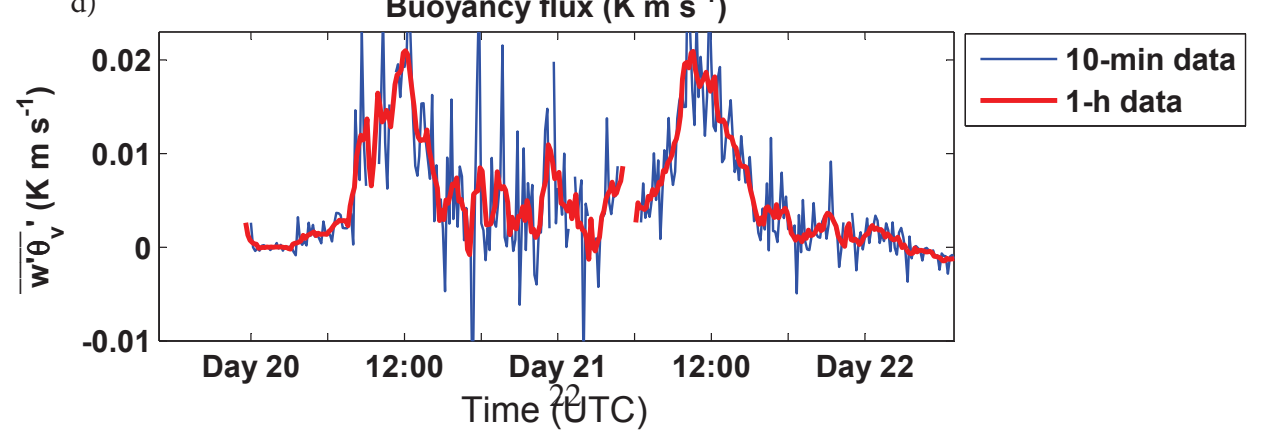

Figure 9: CESAR fog event. a) Comparison between real fog thickness (black line) and the estimated with temperature-convergence (TC) method (red dotted line), with friction velocity measurements and Eq. 2 (blue line) (after averaging $u_{*}$ every hour) and with $u_{*}$ (Eq. 2) for fog with $u_{*}$ $<0.061 \mathrm{~m} \mathrm{~s}^{-1}$ and buoyancy flux and Eq. 4 for fog with $u_{*}>0.061 \mathrm{~m} \mathrm{~s}^{-1}$ (green dotted line) (after averaging values every hour). b) Potential temperature $\left({ }^{\circ} \mathrm{C}\right.$ ) at $2 \mathrm{~m}$ (blue line), $10 \mathrm{~m}$ (black line), $20 \mathrm{~m}$ (red line), $40 \mathrm{~m}$ (green line), $70 \mathrm{~m}$ (magenta line), $140 \mathrm{~m}$ (cyan line) and $200 \mathrm{~m}$ (yellow line). c) Friction velocity $\left(\mathrm{m} \mathrm{s}^{-1}\right)\left(10\right.$-min data (blue line) and 1-h data (red line)). d) Buoyancy flux ( $\left.\mathrm{K} \mathrm{m} \mathrm{s}^{-1}\right)(10-\mathrm{min}$ data (blue line) and 1-h data (red line)). 


\section{Highlights}

- We offer new ways of estimating fog-top height through surface micrometeorological measurements with cheaper instruments tan usually used.

- These methods are based on the relation found between surface turbulence (friction velocity or buoyancy flux) and fog-top height.

- We also evaluate the skill of the estimation of fog-top height through temperature differences between several levels.

- The results are statistically calculated at CESAR (The Netherlands) and CIBA (Spain). 